\title{
A Study About Measuring The Level Of Depression, Anxiety, And Locus Of Control In Asthmatic Women
}

\author{
Shaista Naz \\ Faculty of Education \\ Sindh Madressatul Islam University \\ Nasir Sulman \\ Department of Special Education \\ University of Karachi
}

\begin{abstract}
The purpose of this study was to investigate the relationship between depression, anxiety, and locus of control in mild, moderate, and severe asthmatic women. The analysis focused on the relationship between the severity of illness as a major factor in emotional responding. In order to investigate these relationships, the Beck Depression Inventory, the State-Trait Anxiety Inventory, and the Multidimensional Health Locus of Control Scale were administered to 150 asthmatic women between the ages of 18 to 55 who were being seen for a general medical appointment. The results of the investigation revealed a significant association between asthma severity and psychological functioning. The findings supported the general hypothesis of the study that a significant difference would exist between mild, moderate, and severe asthmatic women in their levels of depression, anxiety, and locus of control.
\end{abstract}

Keywords: Asthma, Depression, Anxiety, Locus of Control, Psychological Functioning

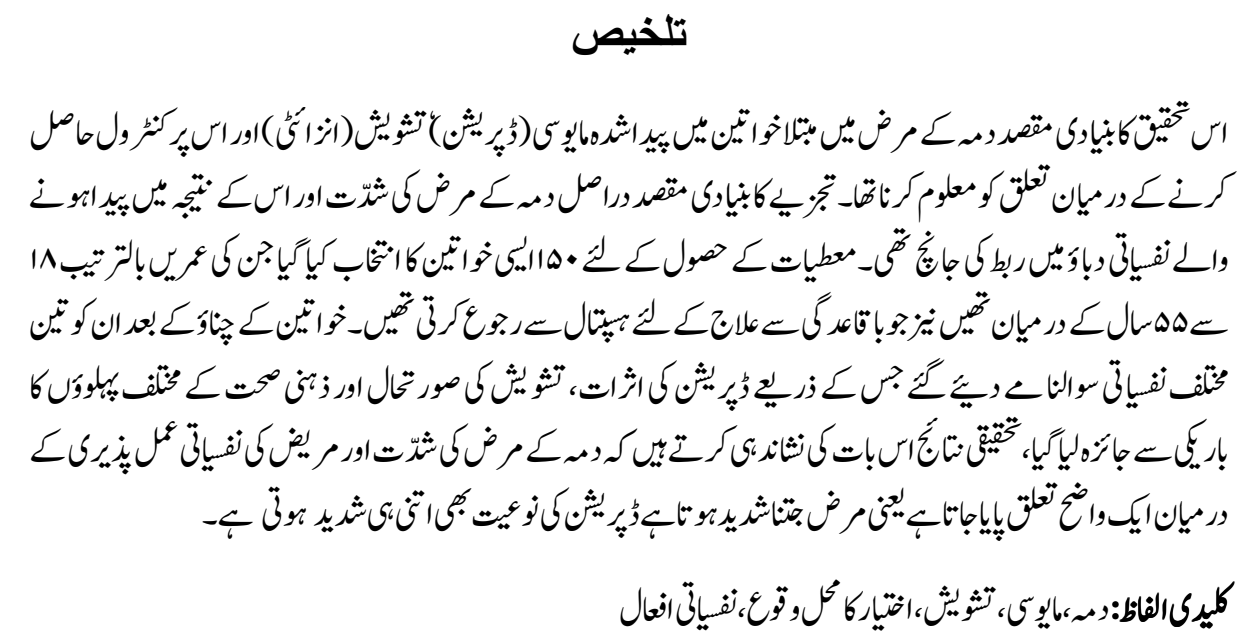


180 A Study about Measuring the Level of Depression, Anxiety, and Locus of Control in Asthmatic Women

\section{Introduction}

Bronchial asthma is a complex, chronic respiratory disorder which afflicts millions of people every year. Though widely recognized as a reversible obstructive airway disease, it is poorly understood in terms of its causality, etiology, and attributions. Considerable evidence now exists to suggest that emotional factors play a role in asthma, and much of the current research in this area has focused on understanding the intricate relationship between psychological factors and the physical components of the disease. In fact, the delineation of the role of such emotional variables may ultimately provide not only greater understanding of how asthma develops, but also insights into the care and management of the illness process.

Depression and anxiety are two of the more prominent variables which have been studied in relationship to asthma. Like many patients with chronic medical illness, asthmatics are left to be at risk for depression (Carlin, 1998; Chaney et al., 1999; Galil, 2000) and patients reporting clinical levels of depression have been found in some cases to have significantly higher levels of asthma (Bell, Jasnoski, Kagan \& King, 1991). The cause of such depression is generally considered to be multifaceted, ranging from difficulty in handling the symptoms of fatigue and disability (Lehrer, Feldman, Giardino, Song \& Schmaling, 2002), to complications resulting from high doses of asthma medications (Thompson \& Thompson, 1984). Loss and extreme disappointment have also been associated with the acute onset of asthma symptoms (Moran, 1995), and depressive conditions have been linked to negative asthma outcomes (Mancuso, Rincon, McCulloch \& Charlson, 2001). Some researchers have indicated that regardless of symptom presentation or improvement, asthma patients present with more depression than other physically ill individuals (Lyketsos, et al., 1984), leading a number of investigators to speculate that such patients may be genetically predisposed toward certain mood disorders (Wamboldt et al., 2000).

Few studies on asthma and asthma psychopathology have looked specifically at adult asthmatics. Most studies have addressed asthma as a childhood disease. While asthma has present most frequently in childhood, virtually two thirds of asthma cases develop after the age of 17 years (Weiss, 1994). In fact, it was not until 1990 that the first guidelines for managing adult asthmatics were published (as cited in O' Byrne \& Thomson, 1995) suggesting a recognition that adult asthma might represent a unique entity, in addition, in child studies that currently exists, there has been little attempt to draw parallels with adult asthma sufferers (Rocco, Barboni, \& Balestrieri, 1998).

The review of the related literature also suggested that less attention has been given to female asthmatics as a group. In one study, Suris, Parera and Puig (1996) looked at chronic illness in adolescent females and found that as a group, they had a much greater prevalence of sadness, depression, moodiness, and suicidal ideation when compared to their normal peers. In a study of women with chronic pulmonary disease, Sexton and Munro (1988) found that the patient's entire family was affected by the illness process. Centanni et al. (2000) noted that asthmatic 
women had more significant levels of anxiety and depression than their male counterparts and Tovt-Korshynska, Dew, Chopey, Spivak, and Lemko (2001) found that women suffering from mild and moderate asthma revealed higher levels of distress compared to other women. Despite the fact that women constitute close to $4 \%$ of the $7.2 \%$ of adults suffering from asthma (Littlejohns, Ebrahim \& Anderson, 1989) and are hospitalized almost twice as often as asthmatic men (Woods, Sorscher, King \& Hasselfeld, 2003), there are currently only a limited number of studies which directly address this population. Therefore, a closer examination of adult women with asthma would have tremendous implications for the field of asthma research.

To consider these facts, the present study investigated the relationship between depression, anxiety and self-esteem in mild, moderate and severe asthmatic women based on the age of onset of their disease. It is believed that understanding the correlates of asthma is an essential step in effectively treating and ultimately managing the illness.

\section{Methodology}

\section{Participants}

The participants in the present study consisted of 150 adult female asthma patients between the ages of 18 and 55 years. Subjects were selected based on their history of asthma and were subsequently categorized into mild, moderate and severe asthma groups. The classification of participants into asthma groups was already performed by the certified pulmonologists who served in Liaquat National Hospital where the sample has drawn. Each asthma group consisted of 50 participants.

The mild asthma group was composed of adults who had asthma symptoms less than once a day, used prescribed medicines or a bronchodilator only when symptoms escalated, had exacerbations which were and may have only slightly affected their activity level, and experienced nocturnal asthma symptoms less than twice a month. The moderate asthma group included an adult female who had daily asthma symptoms, had exacerbations which affected their activity level, required a daily controller medication, and experienced nocturnal symptoms more than once a week. The severe asthma group consisted of female adults who had continuous asthma symptoms and frequent exacerbations, required multiple daily medications to maintain control, had limited physical activity, and experienced frequent nighttime symptoms.

The sample was screened for any physical factors which might have precluded their completion of the study such as severely impaired vision, neurological limitations, or any psychiatric illness which might have rendered them incapable of understanding the purpose of the research. All participants were required to have a minimum of a high school education to ensure adequate comprehension of the study forms and questionnaires. 
182 A Study about Measuring the Level of Depression, Anxiety, and Locus of Control in Asthmatic Women

\section{Research Instruments}

The following instruments were employed in the study and administered according to the standardized instructions:

1. Beck Depression Inventory (BDI)

2. State-Trait Anxiety Inventory, Form Y (STAI)

3. Multidimensional Health Locus of Control Scale, Form C (MHLC)

\section{Beck Depression Inventory}

The Beck Depression Inventory (BDI) (Beck et at., 1961) is a self-report method of assessing the severity of depression. Although the Beck Depression Inventory-II (Beck, Steer, \& Brown, 1996) has emerged in recent years as an updated version of the BDI, for the purposes of the current study, the original BDI was employed because it continues to be more widely used on chronically ill populations (Aben, Verhey, Lousberg, Lodder, \& Honig, 2002; Cassidy, Tomkins, Hardiman, \& O'Keane, 2003; McKellar, Clark, \& Shriner, 2003) and more specifically, with asthmatics (Gillaspy, Hoff, Mullins, Van Pelt, \& Chaney, 2002; Kovacs, Stauder, \& Szedmak, 2003). The BD1 takes only 10 to 15 minutes to administer and is currently one of the most widely used measures of depression.

The BDI is a 21-item inventory, with four self-evaluative statements per item, which respondents rate on a scale from 0 to 3 . The rated responses yield a total score which can range from 0 to 63 . The scores are then categorized as follows:

$0-9(\mathrm{M}=10.9, \mathrm{SD}=8.1)$ indicates no depression or minimal depression,

$10-18(\mathrm{M}=18.7, \mathrm{SD}=10.2)$ suggests mild to moderate depression,

19-29 $(\mathrm{M}=25.4, \mathrm{SD}=9.6)$ reflects moderate to severe depression and

30-63 ( $\mathrm{M}=30.0, \mathrm{SD}=10.4)$ indicates severe depression (Beck, 1967).

\section{State-Trait Anxiety Inventory}

The State-Trait Anxiety Inventory (STAI) (Spielberger, 1983) is a self-report scale based on the principles of state and trait anxiety first proposed by Cattell (1966). The STAI has been used extensively in clinical practice and has frequently been enlisted in medical, surgical, and psychosomatic research (Spielberger, 1983). It has also been employed previously to investigate the role of anxiety in asthma (Alexander, 1972; Kurata, Glousky, Newcomb, \& Easton, 1976).

The STAI consists of two separate 20-item scales designed to measure transient and enduring levels of anxiety, respectively. The State-Anxiety scale asks respondents to indicate how they feel at the moment using a 4-point scale to answer the 20 items. The Trait-Anxiety scale asks respondents to indicate how they generally feel with respect to each of the 20 items, again using a four-point scale. 


\section{The Multidimensional Health Locus of Control Scale}

The Multidimensional Health Locus of Control Scale, MHLC (Form C) (Wallston et al., 1994) is a self-report, general purpose scale, based on the original Multidimensional Health Locus of Control Scales (Wallston et al, 1978). Health locus of control refers to an individual's belief regarding the center of control of their illness. Those with an internal locus of control believe that their own behaviors significantly influence their health, whereas those with an external locus of control feel that their health is influenced by other people or is a result of fate, chance, or luck.

The initial version of MHLC (Form C) consisted of 24 items, with eight Internality, eight chances, and eight powerful other items. Following a factor analysis, the scale was reduced to two 6-item scales for Internality and Chance, and two distinct three-item scales for Powerful Others, which included Doctors and Other People.

\section{Research Design}

Since the current investigation had more than one level of the independent variable and multiple dependent variables, a factorial research design (Campbell \& Stanley, 1963) was employed. This design allowed for the analysis of the relationship between the levels of the independent variable (mild, moderate, and severe asthma groups) and the degree of depression, anxiety, and locus of control as assessed by the dependent measures (BDI, STAI, and MHLC).

\section{Procedure}

The physicians were contacted by the investigator, and a meeting was arranged with each of them to discuss the proposed research. All physicians were given a letter which specified the purpose and format of the study, as well as a copy of the research proposal. If a physician decided that they were interested and wanted to participate, a letter of agreement was signed and returned to the researcher, and study packets were distributed to the physician. The physician subsequently presented all study packets to time office nurse) secretary who was responsible for their distribution. In order to preserve each subject's right to privacy and to protect the confidentiality of time data, all subjects were identified by a random code number only, which appeared at the top of each study packet, as well as at the top of each of the enclosed forms and questionnaires.

During a regularly scheduled office visit, female asthma patients were asked by the duty nurse, if, they would be interested in participating in a research study about asthma. At that time, participants were presented with a letter of solicitation, which provided them with specific information about the study. If the patient agreed, they were then given a packet which they were asked to fill out while in the waiting room. Participants first read a set of 
184 A Study about Measuring the Level of Depression, Anxiety, and Locus of Control in Asthmatic Women

instructions regarding the materials presented to them. Next, they completed the background information form. Participants then completed the questionnaires which included the Beck Depression Inventory (Beck et al, 1961), the State-Trait Anxiety Inventory (Spielberger, 1983), and the Multidimensional Health Locus of Control Scale, Form C (Wallston et al., 1994). Once the participant had finished filling out all forms and questionnaires, they were asked to hand over to same duty nurse which was met by the researcher on a daily basis.

After the study packets had been collected, subjects were classified into one of the three asthma groups. In order to ensure uniformity of diagnosis across physicians, a standardized classification form was filled out by a pulmonologist who was blind to the number of subjects required for each of the asthma groups. Based on the patient's asthma history as recorded on the background information form, the physician classified each of the subjects into either the mild, moderate, or severe asthma groups and then placed the classification form in the subject's study packet. Once the study packet was completed by the participant, scored by the researcher, and classified by the physician, the packet was sealed and stored in a locked filing cabinet in the researcher's office.

The study continued until the required number of study packets was completed for each group. Partially completed study packets and study packets with missing data were eliminated from the final analysis.

\section{Results}

The descriptive statistics for the mild, moderate and severe asthma groups on the BDI, the STAI, and the MHLC are presented in Table 1. The results revealed that with respect to the BD1, subjects from the severe asthma group had the highest average, followed by the mild asthma group and moderate asthma group respectively. The difference between the severe asthma group and the moderate asthma group suggested greater depressive feelings in those subjects suffering from more severe symptoms. On the STAI-State Scale, the severe asthma group achieved the highest average score, followed by the mild and moderate groups. On the STAI-Trait Scale, the mild asthma group had the largest overall average, followed by the severe asthma and moderate asthma groups respectively. Therefore, while the severe asthma group reported the highest level of state anxiety, they did not score the highest on trait anxiety. Scores on the MHLC varied considerably among the different MHLC subscales.

On the MHLC-Internal Scale, the moderate asthma group had the highest overall score, followed by the mild and severe asthma groups. The severe asthma group had the largest mean score on the MHLC-Chance Scale; however, it was only slightly higher than the mean scores achieved by the mild and moderate groups. On the MHLC-Doctors Scale, the moderate asthma group yielded the highest score, followed by the severe asthma group, and the mild asthma group. Finally, on the MHLC-Other People Scale, the severe 
asthma group had the highest average, followed by the moderate and mild asthma groups respectively. Overall, the largest differences in the group mean occurred between the severe asthma group and the mild asthma group. While the severe asthmatics had the highest levels of chance and other people locus of control, it was the moderate asthmatics who scored the highest on the internal and doctors locus of control.

Table

Means and Standard Deviations for the Three Asthma Treatment Groups on the Depression, Anxiety, and Locus of Control Measures

\begin{tabular}{|l|c|c|c|c|}
\hline Variable & Group & n & M & SD \\
\hline BDI & Mild & 50 & 9.20 & 8.09 \\
\hline & Moderate & 50 & 638 & 5.87 \\
\hline & Severe & 50 & 10.48 & 8.99 \\
\hline STAI-State Scale & Total & 150 & 2.82 & 7.86 \\
\hline & Mild & 50 & 41.52 & 13.27 \\
\hline & Moderate & 50 & 36.28 & 10.62 \\
\hline STAI-Trait Scale & Severe & 50 & 43.14 & 11.72 \\
\hline & Total & 150 & 40.31 & 12.20 \\
\hline & Mild & 50 & 41.72 & 12.29 \\
\hline & Moderate & 50 & 36.76 & 9.42 \\
\hline MHLC-Internal Scale & Severe & 50 & 41.36 & 11.66 \\
\hline & Total & 150 & 39.95 & 11.34 \\
\hline & Mild & 50 & 21.68 & 5.86 \\
\hline & Moderate & 50 & 23.52 & 6.07 \\
\hline MHLC-Chance Scale & Severe & 50 & 20.54 & 6.90 \\
\hline & Total & 150 & 21.91 & 6.37 \\
\hline & Mild & 50 & 14.18 & 5.33 \\
\hline & Moderate & 50 & 14.12 & 6.71 \\
\hline MHLC-Doctors Scale & Severe & 50 & 14.50 & 5.55 \\
\hline & Total & 150 & 14.27 & 5.16 \\
\hline & Mild & 50 & 13,56 & $3 .) 1$. \\
\hline & Moderate & 50 & 14.98 & 2.69 \\
\hline MHLC-Other People Scale & Severe & 50 & 13.74 & 3.65 \\
\hline & Total & 150 & 14.09 & 3.22 \\
\hline & Mild & 50 & 6.84 & 3.41 \\
\hline & Moderate & 50 & 6.94 & 3.50 \\
\hline & Severe & 50 & 7.86 & 3.95 \\
\hline & Total & 150 & 7.21 & 3.63 \\
\hline & & & & \\
\hline & & & \\
\hline & & & & \\
\hline & & &
\end{tabular}


186 A Study about Measuring the Level of Depression, Anxiety, and Locus of Control in Asthmatic Women

\section{Summary of Findings}

The results of the current investigation revealed a significant association between asthma severity and psychological functioning. The findings supported the general hypothesis of the study that a significant difference would exist between mild, moderate, and severe asthmatic women in their levels of depression, anxiety and locus of control.

Indeed, it appeared that the severity of asthma symptoms was a contributing factor in the level of psychological impairment and dysfunction suffered by patients. These findings add to the existing research supporting an association between asthma severity and prevalence of psychopathology (Mrazek, 1992; Vila, et al, 1998). Many investigators now believe that there is a well-established connection between the degree of emotional distress, the level of asthma exacerbation, and the potential for severity of symptoms. The implication of the present research is not only those differences exist in the level of psychopathology in asthmatics, but that each group of asthmatics represents a unique category of illness. This is a critical point because previous research that reported contradictory findings when examining emotions and asthma often neglected to classili asthmatics into discrete subgroups. Part of this failure was due to the lack of a reliable system of classification. Wamboldt et al. (1998) speculated that the lack of adequate adult studies as well as the paucity of investigations of women may be factors in the contradictory findings of existing research. Therefore, while the present study reinforces the importance of proper classification of asthmatics, further research aimed at clarifying the unique components of these groups as well as their specific emotional difficulties is imperative.

There are a number of theoretical and clinical implications which can be postulated from the current findings. From a theoretical perspective, the present investigation lends support to the multi-factorial theory (Groen, 1977) which is consistent with a multideterminant model of health (Stoudemire, 1995). Such models not only suggest the interplay of physiological and psychological mechanisms in the illness process, but also concede that certain emotional states influence the development of disturbed patterns of ventilation.

In terms of the clinical impact of the research, the present findings have numerous applications. First, the finding that higher levels of emotional disturbance were noted in more severe asthmatics may facilitate the development of specific psychological therapies to target particular co-morbid conditions. By understanding the elements of asthma severity, as well as the spectrum of psychological factors which might accompany the illness process, clinicians and health care providers can target cognitive strategies, individualized self-management programs, and even symptom perception training for asthmatic patients. 


\section{References}

Aben, I., Verhey, F., Lousberg, R., Lodder, J., \& Honig, A. (2002). Validity of the Beck Depression Inventory, Hospital Anxiety and Depression Scale, SCL-90, and Hamilton Depression Rating Scale as screening instruments for depression in stroke patients. Psychosomatics, vol.43:5, pp.386-393.

Alexander, A. B. (1972). Systematic Relaxation and Flow Rates in Asthmatic Children: Relationship to Emotional Precipitants and Anxiety, Journal of Psychosomatic Research, vol.16, pp.405-410.

Beck, A. T., Ward, C. H., Mendelson, M., Mock, J., \& Erbaugh, J. (1961). An Inventory for Measuring Depression, Archives of General Psychiatry, vol.4, pp.561-571.

Beck, A. T. (1967). The Diagnosis and Management of Depression, Philadelphia: University of Pennsylvania Press.

Beck, A. T., Steer, R. A., \& Brown, G. K. (1996). Manual for the Beck Depression Inventory II, San Antonio. Texas: Psychological Corporation.

Bell, I. R., Jasnoski, M. L., Kagan, J., \& King, D. S. (1991). Depression and Allergies: Survey of a Nonclinical Population, Psychotherapy and Psychosomatics, vol.55, pp.24- 31 .

Campbell, D. T., \& Stanley, J. C. (1963). Experimental and Quasi-Experimental Designs for Research, Boston: Houghton Mifflin.

Carlin, P. A. (1998). Depressed mind, Sick Body, Hippocrates, December.

Cassidy, E. M., Tomkins, E., Hardiman, O., \& O’Keane, V. (2003). Factors Associated with Burden of Primary Headache in a Specialty Clinic. Headache: The Journal of Head and Face Pain, vol.43:6, pp.638.

Cattell, R, B. (1966). Patterns of Change: Measurement in Relation to State Dimension, Trait Change, Liability, and Process Concepts. Handbook of Multivariate Experimental Psychology, Chicago; Rand McNally \& Co.

Centanni, S., DiMarco, F., Castagna, F., Boveri, B., Casanova, F., \& Piazzini, A. (2000). Psychological Issues in the Treatment of Asthmatic Patients. Respiratory Medicine, vol.94:8, pp.742-749. 
188 A Study about Measuring the Level of Depression, Anxiety, and Locus of Control in Asthmatic Women

Chaney, J. M., Mullins, L. L., Uretsky, D. L., Pace, T. M., Werden, D., \& Hartman, V. L. (1999). An Experimental Examination of Learned Helplessness in Older Adolescents and Young Adults with Long-Standing Asthma, Journal of Pediatric Psychology, vol.24:3, pp.259-270.

Galil, N. (2000). Depression and Asthma in Children, Current Opinion in Pediatrics, vol.12:4, pp.331-335.

Gillaspy, S.R., Hoff, A. L., Mullins, L. L., Van Pelt, J.C., \& Chaney, J. M. (2OO2) Psychological Distress in High-Risk Youth with Asthma. Journal of Pediatric Psychology, vol.27:4, pp.363-371.

Groen, J. J. (1977). The Psychosomatic Theory of Bronchial Asthma, Psychotherapy and Psychosomatics, vol.31, pp.38-48.

Kovacs, M., Stauder, A., \& Szedmak, S. (2003). Seventy of Allergic Complaints: The Importance of Depressed Mood. Journal of Psychosomatic Research, vol.54:6, pp.549- 557.

Kurata, J. J., Glousky, M. M., Newcomb, R. L., \& Easton, J. G. (1976). A multiFactorial Study of Patients with Asthma. Part I: Data Collection and Rapid Feedback. Annals of Allergy, Asthma, and Immunology, vol.37, pp.231-245.

Lehrer, P., Feldman, J., Giardino, N., Song, H., \& Schmaling, K. (2002), Psychological Aspects of Asthma, Journal of Consulting and Clinical Psychology, vol.70:3, pp.691- 711

Littlejohns, P., Ebrahim, S., \& Anderson, R. (1989). Treatment of Adult Asthma: Is the Diagnosis relevant? Thorax, vol.44:10, pp.797-802.

Lyketsos, G. C., Karabetsos, A., Jordanoglou, J., Liokis, T., Armagianidis, A., \& Lyketsos, C. G. (1984). Personality Characteristics and Dysthymic States in Bronchial Asthma. Psychotherapy and Psychosomatics, vol.41, pp.177-185.

Mancuso, C. A., Rincon, M., McCulloch, C. E., \& Charison, M. E. (2001), Self- Efficacy, Depressive Symptoms, and Patients' Expectations Predict Outcomes in Asthma. Medical Care, vol.39:12, pp.1326-1338.

McKellar, J.D., Clark, M, E, \& Shriner, J. (2003). The Cognitive Specificity of Associative Responses in Patients with Chronic Pain, British Journal of Clinical Psychology, vol.42, pp.27-39. 
Moran. M. G. (1995). Pulmonary and Rheumatologic Diseases. In A. Stoudemire (Ed.), Psychological Factors Affecting Medical Conditions, Washing-ton: American Psychiatric Press. National Institutes of Health.

Mrazek, D. A. (1992). Psychiatric Complications of Pediatric Asthma. Annals of Allergy, Asthma, and Immunology, vol.69:4, pp.285-290.

O’Byrne, P., \& Thomson, N. C. (1995). Manual of Asthma Management, London: W. B. Saunders.

Rocco, P. L., Barboni, E., \& Balestrieri, M. (1998). Psychiatric Symptoms and Psychological Profile of Patients with Near Fatal Asthma: Absence of Positive Findings. Psychotherapy and Psychosomatics, vol.67, pp.105-108.

Sexton, D. L., \& Munro, B. Z. (1988). Living with a Chronic Illness: The Experience of Women with COPD. Western Journal of Nursing Research, vol.10, pp.26-44.

Spielberger, C. D. (1983). State-Trait Anxiety Inventory: A Comprehensive Bibliography. Palo Alto, C A.: Consulting Psychologists Press.

Stoudemire, A. (1995). Psychological Factors Affecting Medical Conditions. Washington: American Psychiatric Press.

Suris, J. C., Parera, N., \& Puig, C. (1996). Chronic Illness and Emotional Distress in Adolescence, Journal of Adolescent Health, vol.19, pp.153-157.

Thompson, W. L., \& Thompson, T. L. (1984). Treating Depression in Asthmatic Patients, Psychosomatic, vol.25:11, pp.809-812.

Tovt-Korshynska, M. I., Dew, M. A., Chopcy, I. V., Spivak, M. Y., \& Lemko, I. S. (2001). Gender Differences in Psychological Distress in Adults with Asthma, Journal of Psychosomatic Research, vol.51:5, pp.629-637.

Vila, G., Nollet-Clemencon, C., de Blic, J,, Mouren-Sinieoni, M. C., \& Scheinmann, P. (1998). Asthma Severity and Psychopathology in a Tertiary Care Department for Children and Adolescents, European Child and Adolescent Psychiatry, vol.7:3, pp.137-144.

Wallston, B. S., \& Wallston, K. A. (1978). Locus of Control and Health: A Review of the Literature. Health Education Monographs, vol.6, pp.107-117. 
190 A Study about Measuring the Level of Depression, Anxiety, and Locus of Control in Asthmatic Women

Waliston, K. A., Stein, M. J., \& Smith. C. A. (1994). Form C of the MHLC scales: A Condition-Specific Measure of Locus of Control. Journal of Personality Assessment, vol.63:3, pp.534-553.

Wamboldt, M. Z., Fritz, G., Mansell, A., McQuaid, E., \& Klein, R. B. (1998). Relationship of Asthma Severity and Psychological Problems in Children. Journal of the American Academy of Child and Adolescent Psychiatry, vol.37:9, pp.943-950.

Warnboldt, M. Z., Hewitt, J. K., Schmitz, S., Wambolt, F. S., Rasanen, M., Koskenvuo, M. (2000). Familial Association between Allergic Disorders and Depression in Adult Finnish twins. American Journal of Medical Genetics, vol.96, pp.146-153.

Weiss, J. H. (1994). Behavioral Management of Asthma. In B. H. Timinons \& R. Ley (eds.), Behavioral and Psychological Approaches to Breathing Disorders, New York: Plenum Press.

Woods, S. E., Sorscher, J., King, 3., \& Hasselfeld, K. (2003). Young Adults Admitted for Asthma: Does Gender Influence Outcomes? Journal of Women's Health, vol.12:5, pp.481-485.

Dr. Shaista Naz is Assistant Professor in the Faculty of Education, Sindh Madressatul Islam University.

Prof. Dr. Nasir Sulman is Chairman of the Department of Special Education, University of Karachi. 